\title{
What Is a Quantum Society?
}

As a child growing up in the United States, I had understood myself almost wholly in terms of being "an American." This sense of being American can be, as many know, almost spiritual. It is associated with a vision of the good life, a vision of how one relates to one's fellow Americans and to the world at large, and a deep sense of the meaning and importance of one's life and actions so that these adequately reflect American values and bring credit to one's nation and family. Even my early teenage interest in science was awakened as much by a desire to serve America as by a fascination with atomic physics itself. But when I was in my late teens and early twenties, I lost all this. When I was nineteen, President John Kennedy was assassinated, and this was followed in deep succession by the assassinations of Martin Luther King, Bobby Kennedy, and America's deep involvement in the Viet Nam war. Some dark and irrational forces seemed bent on destroying all that was best in my society and what it stood for, and the whole edifice of my childhood beliefs came tumbling down.

For many years after finishing my university studies, I lived as an expatriate in foreign lands, feeling no desire to belong to any society. But when my young children were born, I began to imagine what kind of society I would like them to grow up in, what social values I would hope they could cherish. At that same time, people who had read my book The Quantum Self were writing to ask me what I thought a "quantum society" would be like. America was beginning its long slide into what

(C) The Author(s) 2022

D. Zohar, Zero Distance, https://doi.org/10.1007/978-981-16-7849-3_21 
ultimately became Trumpism, and I did not feel that the Britain I was living in at the time had all the qualities I would imagine in such a society. Relying instead on describing what kind of society I hoped and thought could arise if it were founded on the principles and values that underpin the quantum world view, I wrote my book The Quantum Society. That was many years ago, and my thinking about an ideal, "quantum," society has of course evolved. In the wake of Covid-19 social failures, both I and many others are asking, "What kind of society would we like to become?"

\section{A Complex Adaptive System Grounded IN THE WhOLE}

To most people, the world of physics seems remote. Its abstract mathematical formulae and complex experimental results seem to bear no relation to the concerns of everyday life, to the passions that we feel, the kinds of decisions that we make, or to the nature of our society or our social institutions. Yet we human beings are physical creatures. The dynamics of both our bodies and our minds are guided by the same laws and forces that move the sun and the moon or that bind atoms together, and we are members of earth's living system. Quantum science tells us there is just one reality, and we and everything about us are part of that. Our societies are part of it, a part of the larger whole. Thus, ideally, our societies will mirror the same features and creative dynamics that distinguish everything else in our quantum universe.

In Part II of this book, we saw that we are "quantum selves," both particle-like and wave-like, individuals and yet defined through our relationships, manifold in our identities, our lives enfolded within everything and everyone, and everything and everyone enfolded within us. Our social lives should reflect those same balanced, mutually beneficial polarities, defining relationships, celebration of diversity, and holism. In Part IV, we saw the possibility of "quantum organizations" possessing these qualities, companies that are sustainable, innovative, and evolutionary when they are led and structured to function as living quantum systems, "complex adaptive systems" - and that the secret of our great cities' creative complexity is that they have naturally evolved as such systems.

We have seen that all complex adaptive systems are self-organizing, holistic, emergent (creative), exploratory, thrive on diversity, are poised at the edge of chaos (flexible and adaptive), and are in a co-creative dialogue 
with their environment. So it seems wisest that a quantum society should have the society-wide equivalents of those qualities and systems dynamics.

\section{Individuals, Citizens, ANd Members of the Natural World}

One of the main challenges of our times is to link the inner world and value of the self with the outer world of society, and to see both within the larger context of the natural world. I believe this includes a spiritual challenge to link both individuals and societies with something larger than ourselves that will restore a lost sense of higher meaning to all our projects, both personal and social. This challenge is most urgent in the Western world, where exaggerated individualism has led to selfishness and lack of responsibility toward each other, and where the Newtonian assumption that human beings are separate from both the universe and nature has led to the exploitation of our fellow creatures and the earth's resources. At the same time, the traditional values of some Eastern societies can ignore or inadequately appreciate the importance or value of the individual. And since the Industrial Age, a careless, Newtonian disregard for Nature and the earth's environment has been shared by all developed and developing modern nations, regardless of whether they once had a more traditional sense of being fully part of and responsible for Nature and the wider universe.

We have seen that the sustainability and creativity of complex adaptive systems depend in part on each individual element of the system being healthy, and playing its unique role in the dynamics of the whole system. CADs are composed of important parts whose own nature and functions can then combine to create the complex web of relationships that make the emergent system larger than the sum of its parts. For that reason, both Quantum Management, and the RenDanHeyi model for implementing its principles in companies, stress the importance and infinite nature of individual human potential, and thus quantum companies embrace values and build structures that strive to maximize each employee's individual ability fully to realize his/her potential. I referred to this as the particlelike nature of the quantum organization.

Quantum societies, too, must possess a particle-like nature, values that stress the importance and value of individuals, and social and political structures that enable each individual to achieve his/her own best personal potential. Such societies take responsibility for the needs of, 
nurture the cultivation of, and provide opportunities for individuals, knowing this best serves the needs and cultivation of society as a whole. Quantum societies thus ensure each individual has quality health care, a high standard of education, access to public and cultural facilities, community environments that cultivate "body, mind, and spirit," support in times of need and old age, and the personal freedom to benefit from these, each in his/her own way.

But both quantum organizations and quantum societies also have a wave-like nature, the emergent, collective whole of which employees and individual citizens are a part. The collective, wave-like nature of a quantum society is the shared public space and public institutions, the shared, mutual responsibility to and for each other, and the shared meanings and values that are the cultural glue binding the society together, the sense that we all belong to each other as members of one family. These meanings and values differ in different cultures and societies, but in any quantum society, they will include mutual respect, mutual responsibility, compassion, a celebration of diversity, social harmony, and a shared sense that the society as a whole possesses a higher meaning and purpose due to its role in the shared purpose of human life itself, and humanity's role in Nature and the cosmos. This sense of its higher meaning and purpose is reflected back to members of the society through public symbols and aesthetics that themselves reflect beauty, balance, harmony, collective belonging, and the presence of Nature. The quantum society is an extended family, and its shared public spaces are an extended home.

And just as we quantum individuals find much of our personal identity through our wave-like relationships with others, our membership of a quantum society broadens that sense of identity through relationship with the social whole. It also broadens the meaning and purpose of our personal lives as we realize that our personal self-cultivation and transformation is the vehicle for social transformation and a cultivated society. In improving myself, I am improving the lives of all. Quantum physics teaches us that we make the world and are thus responsible for the world. The quantum individual makes society, takes responsibility for society, and discovers more of him/herself through being part of society.

As I write about the relationship between quantum individuals and the spontaneously self-organizing quantum societies of which we are a part, I have in mind the image of a free-form dance company-each member a soloist in his or her own right, but moving co-creatively in harmony with others. Each soloist stands out as an individual, and yet the dance they 
make together emerges as a new, further reality. The dance, the "work of art" or the "production," has a reality of its own over and above the separate and freely moving identities of the individual dancers; each dancer, while remaining distinctly him or herself, acquires a new, further identity-member of the company.

Yet, having said all this, we can see how very far those of us in most Western societies are from being either quantum selves or from living in a quantum society. In today's Western societies, we are all soloists without a production company, all primidone's. The freedom and rights of the individual that underpin the democratic ideal have become an exaggerated "me first": my right as a free individual to do whatever I like, regardless of any cost, harm, or consequences to others. We heard this daily on the media during the Covid crisis from Americans who declared that it was their "right as free Americans not to wear a mask." On a BBC broadcast about the need for us all to pull together, observe lockdown rules, and protect each other as a family, a prominent journalist protested, "England is not my family! My family is my family, and it is the government's responsibility to protect our right to live and go about our business as we want."

These people see themselves as isolated atoms bouncing about in an anonymous and amoral social space with no purpose or meaning of its own. As Britain's Mrs. Thatcher once famously stated, "There is no such thing as 'society." But basic physics and our own biological nature tell us this is delusional thinking. We live in a symbiotic world of Zero Distance in which everything is entangled with everything, everyone is part of and within everyone else. Every element of the cosmos and biosphere is an element in a larger system, dependent upon and responsible for the sustainability of that system. Society is a larger system of which we individuals are a part. It has an existence and an identity of its own. There is no "me" without "us," no "mine" without "ours," no "citizens" without society.

\section{A Community of Communities}

Selfish individualism is not the only force fragmenting Western societies today. In most of today's Western democracies, social consciousness and the political loyalties which express it are dominated by populist "identity politics." Egged on by unprincipled politicians wishing to mask their own multiple failures to address the very real social and economic deprivations 
of working-class voters, social individuals have come to see themselves, not as fellow citizens, but as members of a racial, religious, minority ethnic, or special-interest identity group. Difference, not commonality or more inclusive kinship is emphasized, and every identity group different from mine is "other," a threatening other whose expectations of inclusion and equality would destroy "us" and everything "we" cherish about "our society." Today there are "African Americans," "Native Americans," "Hispanic Americans," "white Christian Americans," "Muslim and Jewish Americans," but no just plain "Americans." In Europe, there are "Citizens" and "Immigrants," in Brexit Britain, "Leavers" and "Remainers." All "tribes" threatened by other "tribes."

In their more positive form, ethnic "tribes" are known as "communities," and in more healthy, pluralist societies, communities enjoy a sense of dual identity. Like the individuals of which they are composed, each community has a "core," or particle aspect, and an "integrated," or wave aspect. Each is both a solo dancer and a member of the dance company, and is thus both self and others, others with whom it shares the public space and national life of the society. This is the ideal of a quantum society, which I describe as a "community of communities." Before populist fragmentation set in, the great American "melting pot" was such a community of communities, with Italian, Irish, Polish, etc. communities both celebrating the identity and customs of their countries of origin and at the same time celebrating a shared identity and national customs with all other Americans. This rich mix of dual-identity communities, and its celebration of diversity, was America's unique strength. Its overall national culture was a quantum-like superposition of individualist personal cultures and a more collective, ethnically integrated, community culture. It is a hope of returning to this that Americans today long for when they speak of their need for "national healing," but now any such healing must also bridge the chasm between the wealthy few and the deprived many.

\section{Dialogue: The Conversation of a Quantum Society}

Complex quantum societies celebrate diversity and reap its benefits, but when people of different backgrounds, different needs, and who hold often quite different opinions live together, we must have ways to communicate our commonality and communality, our tolerance and mutual respect. We do so through shared symbols and shared public 
celebrations, but the most powerful and unique way that human beings communicate is through language, through the conversations we have with one another and the public conversations of our society. In today's Western societies that have been fragmented by populist divisions and plagued by the misinformation and sometimes utter abandonment of truth enabled by social media, the public conversation is angry, and dominated by opposition. But even in better times, the preferred Western mode of conversation has long been "debate."

Debate is by its very nature pugilistic, each side intentionally adopting opposing positions and then battling it out to see which can beat down the other's argument and "win." Debate is either/or discussion. If I am right, you have to be wrong; if I win, you have to lose. If my argument is stronger, yours has no validity, thus denying any possibility there can be two sides to a question, two ways to look at an issue. Such a speaking posture can only emphasize differences, and force people into positions of attack or defense. It invites black and white thinking and assumes that the more certain one's adopted argument, the more likely it is to be "winning." Debate thus discourages the critical thinking and humility required in a quantum society for people honestly to question their own and others' assumptions and finally breakthrough to a creative reframing that results in a wider, and often shared, perspective. It discourages shared exploration and mutual discovery.

Dialogue, by contrast, is an open-ended, open-minded form of conversation intended especially to facilitate shared exploration and mutual discovery. First conceived by Socrates as a method of teaching that was intended to make students question their assumptions and surface knowledge they didn't know they possessed, it was also used by the citizens of ancient Athens to get beyond conflicts and arrive at new solutions. Where debate is about knowing what is best, dialogue is about exploring all options and points of view and finding out what is best. In a debate, I have all the answers, and want to convince the other to accept them; in dialogue, I ask myself and others questions. Debate is a zero-sum game that only one of us can win; dialogue finds validity in many points of view and arrives at win/win outcomes from which everybody gains. Debate is about wielding power, my power to prove you wrong; dialogue is about listening and respect, my respect for the possible truth in what you say. Debate never produces new breakthroughs of understanding nor results in previously unforeseen solutions. The loser just accepts what the winner already knew. But dialogue is an emergent conversation in 
which breakthrough insights are larger than the sum of all original, individual opinions or ideas. Debate is "Newtonian" conversation, dialogue "quantum" conversation.

The either/or, one-best-way Western mindset has always found debate its natural mode of conversation, and this has always meant that society is characterized by opposition, confrontation, and dissent. In today's very fragmented democratic societies, this has morphed into an angry, almost warring, and fractured public conversation in which nobody listens to any point of view other than his/her own. Opposing political factions are paralyzed by ideological deadlock, and thus society's needs are not addressed by workable, agreed-upon solutions. Society is ineffective and lacking in harmony.

Quantum societies seek social harmony built upon tolerance, mutual respect, and the celebration of diversity. They seek win/win outcomes when different needs and interests must be satisfied. Their creative evolution requires the constant emergence of innovative ideas and solutions, and these arise from exploring multiple possibilities. Quantum societies need conversations that are quantum in nature, and dialogue is thus their natural mode of conversation.

Open Access This chapter is licensed under the terms of the Creative Commons Attribution-NonCommercial-NoDerivatives 4.0 International License (http:// creativecommons.org/licenses/by-nc-nd/4.0/), which permits any noncommercial use, sharing, distribution and reproduction in any medium or format, as long as you give appropriate credit to the original author(s) and the source, provide a link to the Creative Commons license and indicate if you modified the licensed material. You do not have permission under this license to share adapted material derived from this chapter or parts of it.

The images or other third party material in this chapter are included in the chapter's Creative Commons license, unless indicated otherwise in a credit line to the material. If material is not included in the chapter's Creative Commons license and your intended use is not permitted by statutory regulation or exceeds the permitted use, you will need to obtain permission directly from the copyright holder.

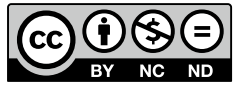

